Article

\title{
Research on the Microstructures and Mechanical Properties of Bainite/Martensite Rail Treated by the Controlled-Cooling Process
}

\author{
Jiajia Qiu ${ }^{1}$, Min Zhang ${ }^{1, *}$, Zhunli Tan ${ }^{1}$, Guhui Gao ${ }^{1}$ and Bingzhe Bai ${ }^{1,2}$ \\ 1 School of Mechanical, Electronic and Control Engineering, Materials Science and Engineering Research \\ Center, Beijing Jiaotong University, Beijing 100044, China; 17121353@bjtu.edu.cn (J.Q.); \\ tzli@bjtu.edu.cn (Z.T.); gaogh@bjtu.edu.cn (G.G.); bzbai@bjtu.edu.cn (B.B.) \\ 2 Key Laboratory of Advanced Materials of Ministry of Education, School of Materials Science and \\ Engineering, Tsinghua University, Beijing 100084, China \\ * Correspondence: zhangm@bjtu.edu.cn
}

Received: 22 August 2019; Accepted: 18 September 2019; Published: 20 September 2019

\begin{abstract}
A bainite/martensite multiphase rail is treated by the controlled-cooling process with different finish-cooling temperatures. The simulated temperature-time curves of the position of $5 \mathrm{~mm}$ and $15 \mathrm{~mm}$ below the rail tread (P5 and P15) express different trends. P5 has greater impact toughness and lower tensile strength than P15. Microstructural characterization was carried out by conducting scanning electron microscopy, X-ray diffraction, electron backscatter diffraction, and transmission electron microscopy. The greater tensile strength is due to the dispersed $\varepsilon$-carbides hindering the movement of dislocations. The greater impact toughness is attributed to the filmy retained austenite and the smaller effective grain with high-angle boundary. Finite element modeling (FEM) and microstructural characterization reasonably explain the changes of mechanical properties. The present work provides experimental and theoretical guidance for the development of rail with excellent mechanical properties.
\end{abstract}

Keywords: bainite/martensite multiphase rail; high-angle boundary; controlled-cooling process; decomposed martensite; crack initiation

\section{Introduction}

Heavy-duty and high-speed railway transportation brings about increased stress on rail and worsening operating conditions. Rail damage is also increased, such as peeling, concealing or even fracture, due to wear and fatigue. Therefore, it is important to increase the strength of rail that can improve wear resistance and prolong service life. The research and development of next-generation rail focuses on enhancing mechanical properties $[1,2]$. Low-carbon bainite/martensite (B/M) multiphase rail has been successfully used in some heavy haul railway and has much potential to substitute the traditional pearlite rail due to its excellent mechanical properties [3-5]. The conventional production process of $\mathrm{B} / \mathrm{M}$ multiphase rail is air-cooling after hot rolling, which is susceptible to seasonal and regional impact. The controlled-cooling process can reduce the impact of environment and improve the uniformity of microstructures. It has been proved to refine the intragranular microstructure of steel, which in turn improves mechanical properties, such as strength and impact toughness $[6,7]$.

In recent years, finite element modeling has been widely applied in the manufacturing of rail. It can simulate the microstructure evolution and temperature changes in the different positions of rail, which contributes to design and optimization of the cooling process after hot rolling [8,9]. Changing the cooling process could yield different types of microstructural phases (e.g. bainite ferrite, martensite, retained austenite, and even $\varepsilon$-carbide) coexisting as microstructural constituents in B/M multiphase 
rail steel, which influence mechanical properties through its morphology, content, and size [10]. A number of studies have shown that the effective grain with high-angle boundary can disrupt crack propagation, i.e., the propagation direction changes at these boundaries and the crack propagation path increases [11-13]. Filmy retained austenite (RA) with higher carbon content has superior stability and acts as an obstacle during crack propagating [14-16]. That can be favorable to improve the service life of rail steel. A large number of dispersed $\varepsilon$-carbides can hinder the movement of dislocations and produce precipitation strengthening, which are good for the improvement of mechanical properties $[17,18]$.

The present study focuses on the microstructures and mechanical properties of the industrially produced $\mathrm{B} / \mathrm{M}$ rail steel through the controlled-cooling process with different finish-cooling temperatures. Due to microstructure segregation and the largest shear stress, the actual engineering application pays more attention to the microstructure and mechanical properties of the position of $5 \mathrm{~mm}$ and $15 \mathrm{~mm}$ below rail tread. The effect of microstructures on mechanical properties in these positions has been researched in-depth, involving electron microscopy, tensile, and impact test. The work can provide a scientific and systematic guidance for the development of the high strength and toughness rail.

\section{Experimental Procedures}

The chemical composition of bainitic/martensite rail steel is $0.22 \mathrm{C}-2.0 \mathrm{Mn}-1.0 \mathrm{Si}-0.8 \mathrm{Cr}-0.8(\mathrm{Mo}+\mathrm{Ni})$ (wt $\%)$. The spray cooling process was adopted to control cooling speed of the rail-head after rolling. The surface of the rail-head was cooled by the spray mist, while the rest of the rail was naturally cooled. When the surface temperature of the rail-head decreased to finish cooling temperatures (Tq) of $230{ }^{\circ} \mathrm{C}$, $250{ }^{\circ} \mathrm{C}$, and $280^{\circ} \mathrm{C}$ (abbreviated T230, T250, and T280, respectively), the spray controlled-cooling process was stopped, and then the whole rail adopted the air-cooling process.

The volume fraction of RA ( $\left.\mathrm{X}_{\mathrm{RA}}\right)$ was measured by X-ray diffractometer (Rigaku Smartlab, Rigaku Corporation, Tokyo, Japan, $\mathrm{Cu}$ Ka radiation) at a step of $0.01^{\circ}$ and a counting time of $2 \mathrm{~s} / \mathrm{step}$ using $10 \mathrm{~mm} \times 10 \mathrm{~mm} \times 2 \mathrm{~mm}$ samples. $X_{R A}$ was estimated by collecting the peak intensities of $(200) \gamma,(220) \gamma,(311) \gamma,(200) \alpha$, and (211) $\alpha$. The precise austenite lattice constant $\left(\mathrm{a}_{\gamma}\right)$ was obtained by Nelson-Riley extrapolation method. The carbon content of retained austenite $\left(\mathrm{X}_{\mathrm{C}}\right)$ can be estimated using Equation (1):

$$
\mathrm{a}_{\gamma}=3.556+0.0453 x_{\mathrm{C}}+0.00095 x_{\mathrm{Mn}}+0.0056 x_{\mathrm{Al}}
$$

where the austenite lattice $\mathrm{a}_{\gamma}$ is in $\AA$, and $x_{\mathrm{C}}, x_{\mathrm{Mn}}$, and $x_{\mathrm{Al}}$ are the concentrations of carbon, manganese, and aluminum, respectively, in wt \%.

Microstructures were characterized by scanning electron microscopy (SEM; ZEISS-EVO18, $20 \mathrm{kV}$, Carl Zeiss Microscopy Ltd., Cambridge, UK) after polishing and etching in 3\% nital solution. The specimens for transmission electron microscope (TEM; JEOL F200, 200 kV, JEOL, Tokyo, Japan) were electropolished at $-30{ }^{\circ} \mathrm{C}$ using $6 \%$ perchloric acid solution. Auger electron spectroscopy (AES, ULVAC-PHI, Inc., Chigasaki, Japan) was applied for electron backscatter diffraction (EBSD) measurements utilizing a PHI 710 microprobe operating (ULVAC-PHI, Inc., Chigasaki, Japan) at $20 \mathrm{kV}$ with a step size of $0.1 \mu \mathrm{m}$. And the scanning area is $40 \mu \mathrm{m} \times 40 \mu \mathrm{m}$, which can cover about five prior austenite grains.

Specimens were cut from the rail-head in the rolling direction as shown in Figure 1. Standard tensile samples with a gage diameter of $5 \mathrm{~mm}$ and a gage length of $25 \mathrm{~mm}$ were prepared for tensile tests using a SUNS 5305 tensile testing machine (MTS Systems, MTS, Shanghai, China). Two samples were tested for each process. An extensometer and a force sensor were used. Impact tests were performed using standard Charpy U-notch specimens $(10 \mathrm{~mm} \times 10 \mathrm{~mm} \times 55 \mathrm{~mm}$, standard EN10045) using JBDS-300B impact tester device (Wuzhong Material Test Ltd, Wuzhong, China) at $20^{\circ} \mathrm{C}$. Three specimens were used for each test. 


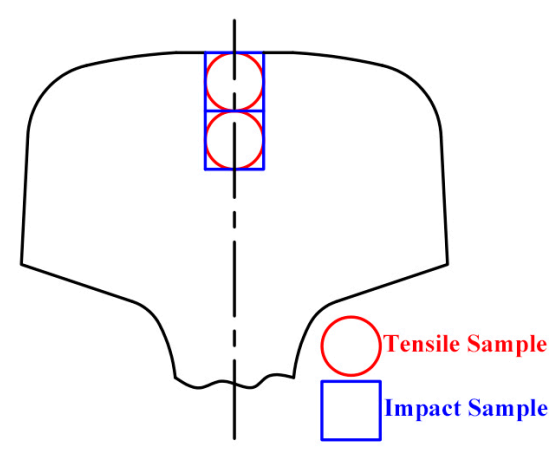

Figure 1. Schematic diagram showing the sampling positions in the rail-head.

\section{Results and discussion}

\subsection{FEM Simulation of the Controlled-Cooling Process}

The controlled-cooling processes of T230, T250, and T280 after rolling are simulated by finite element modeling (FEM). Temperatures of different positions such as tread, the position of $5 \mathrm{~mm}$ below rail tread (P5), and the position of $15 \mathrm{~mm}$ below rail tread (P15), as indicated in Figure 2a, can be obtained. Part of temperatures with respect to the cooling time in the controlled cooling processes (T230, T250, and T280) are respectively presented in Figure $2 \mathrm{~b}-\mathrm{d}$. The cooling rate at each position of rail-head reduce due to the latent heat of phase change when the temperature decreases below $400{ }^{\circ} \mathrm{C}$. The temperature of tread is about $50{ }^{\circ} \mathrm{C}$ lower than that of $\mathrm{P} 15$. The curves of temperature-time of different positions in rail-head, shown in Figure $2 b-d$, express different trends when the surface of rail-head is changed from the spray controlled-cooling process to the air-cooling process. Temperatures of tread and P5 begin to increase due to the latent heat of phase change and the internal heat transfer while temperatures of P15 decrease very slowly. Then temperatures at all positions reach a stable plateau, which lasts for about $10 \mathrm{~min}$.
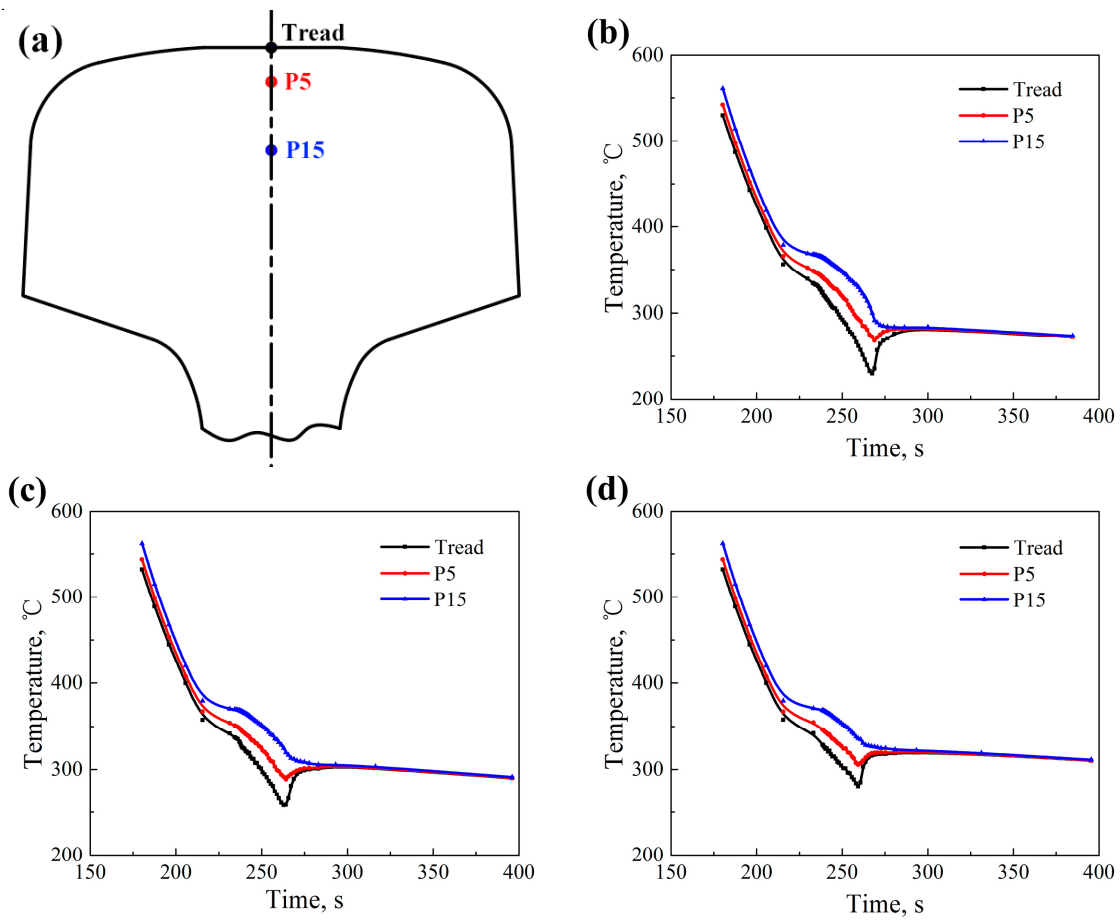

Figure 2. Finite element modeling (FEM) simulation results: (a) The sampling positions in the rail-head (Tread, P5, and P15); (b-d) Temperatures with the cooling time in different processes (T230, T250, and $\mathrm{T} 280$, respectively). 


\subsection{Mechanical Properties}

The mechanical properties at different tread-head positions treated by different processes are summarized in Table 1. All rail samples exhibit a good combination of tensile strength (above $1320 \mathrm{MPa}$ ) and impact toughness (above $90 \mathrm{~J}$ ). The impact toughness of P5 is about $30 \mathrm{~J}$ greater than that of P15. Furthermore, the T280-P5 sample reaches a maximum value of $131 \mathrm{~J}$. The tensile strength of P5 decreases from $1402 \mathrm{MPa}$ to $1322 \mathrm{MPa}$ and that of P15 from $1504 \mathrm{MPa}$ to $1379 \mathrm{MPa}$ when the Tq increases from $230{ }^{\circ} \mathrm{C}$ to $280^{\circ} \mathrm{C}$. At the same time, the yield strength of $\mathrm{P} 5$ decreases from $1295 \mathrm{MPa}$ to $1201 \mathrm{MPa}$ and that of P15 from $1272 \mathrm{MPa}$ to $1181 \mathrm{MPa}$. The strength of samples increases as the Tq decreases, which is caused primarily by the different martensite content in the samples. The content of the prior martensite increases with the decrease of finish cooling temperature as Koistinen-Marburger relationship describes. Usually the larger martensite amount results in a higher strength. The tensile strength of P5 is about $50 \mathrm{MPa}$ lower than that of P15 in the same rail. For samples of P5, the residual internal stress may get decreased and carbon atoms diffuse out of the martensite when temperature increases after the spray controlled-cooling process completed, which may reduce the tensile strength of the samples [19].

Table 1. Mechanical properties of different rail-head positions with different processes.

\begin{tabular}{ccccc}
\hline Condition & Tensile Strength $\mathbf{( M P a )}$ & Yield Strength $\mathbf{( M P a )}$ & Elongation $\mathbf{( \% )}$ & Toughness $(\mathbf{J})$ \\
\hline T230-P5 & $1402 \pm 11$ & $1295 \pm 5$ & $13.3 \pm 0.1$ & $121 \pm 2$ \\
T250-P5 & $1391 \pm 2$ & $1243 \pm 12$ & $14.5 \pm 0.1$ & $124 \pm 2$ \\
T280-P5 & $1322 \pm 6$ & $1201 \pm 6$ & $15.5 \pm 0.1$ & $131 \pm 2$ \\
T230-P15 & $1504 \pm 2$ & $1272 \pm 0$ & $12.5 \pm 0.1$ & $92 \pm 1$ \\
T250-P15 & $1445 \pm 3$ & $1215 \pm 3$ & $13.8 \pm 0.2$ & $97 \pm 3$ \\
T280-P15 & $1379 \pm 4$ & $1181 \pm 0$ & $14.9 \pm 0.1$ & $105 \pm 0$ \\
\hline
\end{tabular}

\subsection{Microstructure Characterization}

The SEM micrographs of samples at the positions of $5 \mathrm{~mm}$ and $15 \mathrm{~mm}$ below rail tread, taken from the rolling direction of rails, are respectively shown in Figure 3. The microstructures at different positions contain martensite and a small amount of bainite and retained austenite. The lath-like microstructures of samples are clearer and significantly finer with the finish-cooling temperature decreasing. The lower the finish-cooling temperature, the larger the nuclear driving force of phase transformation. The probability of mutual interference and collision between the growing laths increases, reducing the size of the lath martensite [20], which results in greater strength of T230 samples compared with that of T280 samples. According to the continuous cooling transformation (CCT) curves of rail steel shown in reference [21], changing cooling rates could yield different types of microstructures. The content of martensite increases with the increasing of cooling rate in the continuous-cooling process. The martensite content of P5 is more than that of P15 because the cooling rate close to the surface of the rail-head is faster. Interestingly, more martensite content does not result in greater tensile strength.

Figure 4 indicates the TEM micrographs of samples at the positions of $5 \mathrm{~mm}$ and $15 \mathrm{~mm}$ below rail tread treated by the T280 process. Figure 4a shows that the morphology of retained austenite in the T280-P5 sample is almost filmy and it distributes between martensite laths. Figure $4 \mathrm{~d}$ expresses that the retained austenite of the T280-P15 sample exists in blocky martensite/austenite (M/A) constituents distributing around martensite laths. The size of blocky M/A constituents is much larger than that of filmy RA. The filmy RA is more mechanically stable than the blocky ones because of the higher carbon content. The blocky M/A constituents are easily transformed into martensite at low temperature or by exertion with external force, which may become crack sources resulting in lower impact toughness. It has been reported that the filmy RA can improve the impact toughness by inhibiting the formation of micro-cracks and suppressing the crack propagation $[10,22]$. There is a small amount of $\varepsilon$-carbide precipitation within the ferrite plates and they form parallel arrays at about $60^{\circ}$ to the axis of the 
ferrite plates, as shown in references $[23,24]$. Figure $4 c, d$ indicate that the $\varepsilon$-carbide precipitation in the T280-P15 sample is much more than that in the T280-P5 sample. A large number of dispersed $\varepsilon$-carbides can hinder the movement of dislocations and produce precipitation strengthening, which may explain why the tensile strength of P15 is greater than that of P5.
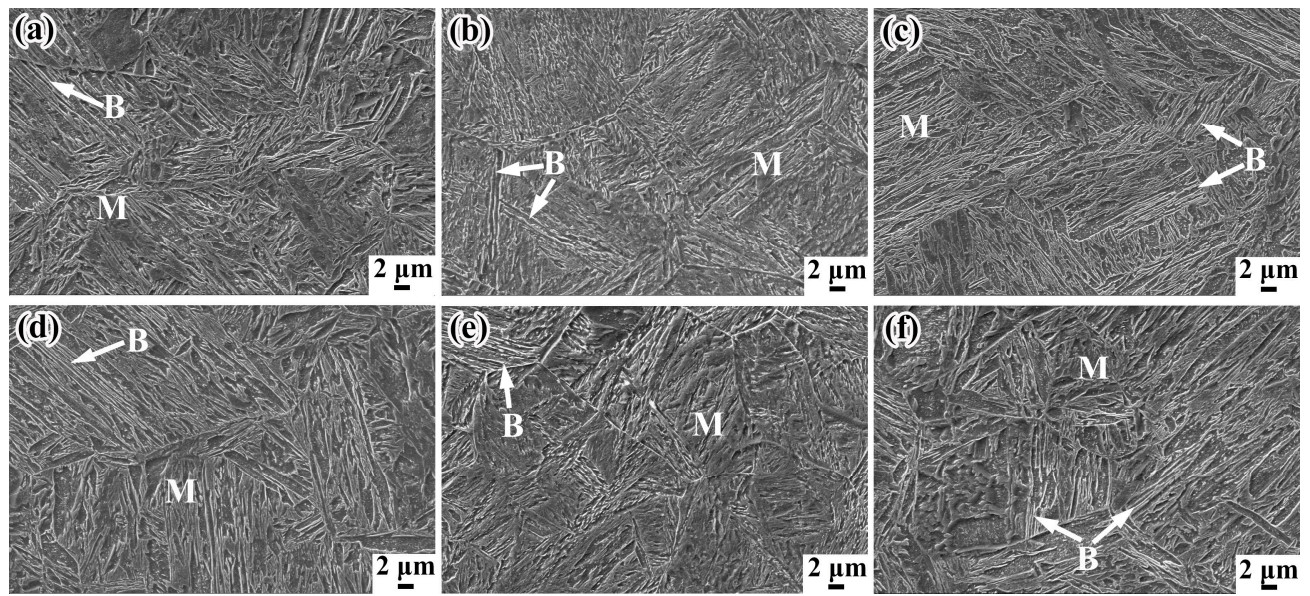

Figure 3. Scanning electron microscopy (SEM) of samples at the positions of $5 \mathrm{~mm}$ and $15 \mathrm{~mm}$ below rail tread treated by different process: (a) T230-P5; (b) T250-P5; (c) T280-P5; (d) T230-P15; (e) T250-P15; (f) T280-P15.
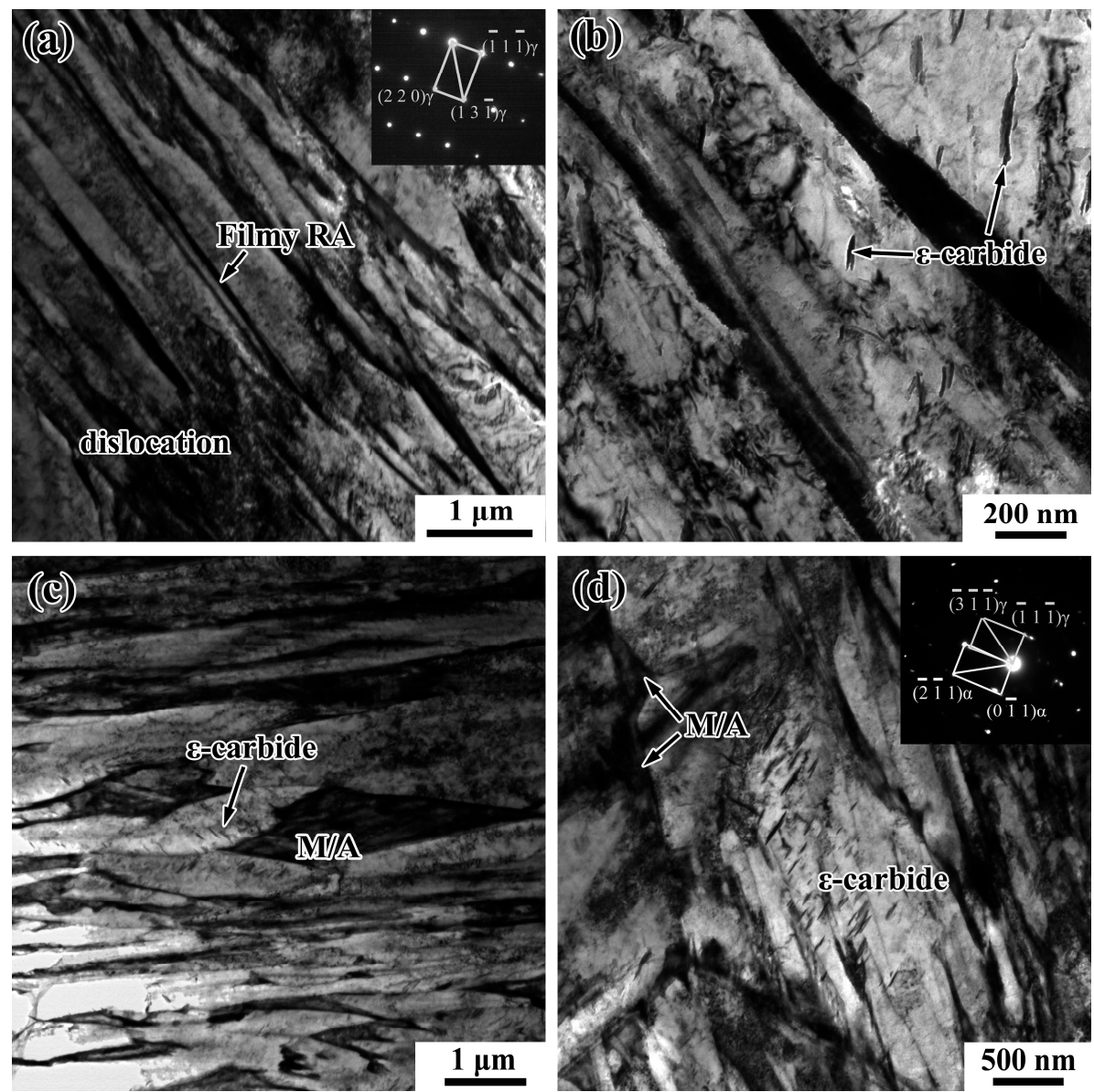

Figure 4. Transmission electron microscope (TEM) of samples at the positions of $5 \mathrm{~mm}$ and $15 \mathrm{~mm}$ below rail tread treated by T280 process: (a,b) T280-P5; (c,d) T280-P15. 
XRD patterns of different samples are shown in Figure 5a. The volume fraction of retained austenite and carbon content of retained austenite are presented in Figure $5 b, c$. $X_{R A}$ increases with the Tq increasing from $230{ }^{\circ} \mathrm{C}$ to $280{ }^{\circ} \mathrm{C}$. The samples of $\mathrm{P} 15$ have greater $\mathrm{X}_{\mathrm{RA}}$ than samples of P5 in the same rail. The smaller $\mathrm{Tq}$, the greater content of austenite transforming to martensite, which leads to smaller volume fraction of retained austenite. Carbon atoms will diffuse from martensite with higher chemical potential to retained austenite when the spray controlled-cooling process changes to the air-cooling process, which can increase the carbon content of retained austenite. The retained austenite with lower carbon content will continue to undergo phase transformation to form martensite, while the one with sufficient carbon content will become more stable. The $\mathrm{X}_{\mathrm{C}}$ of the P5 samples is greater than that of the P15 samples in the same rail. As discussed earlier, the samples of P5 have much more $\varepsilon$-carbide precipitation than the samples of P15. The carbide precipitation increases the carbon consumption, which results in greater $\mathrm{X}_{\mathrm{C}}$ of the $\mathrm{P} 5$ samples.

(a)

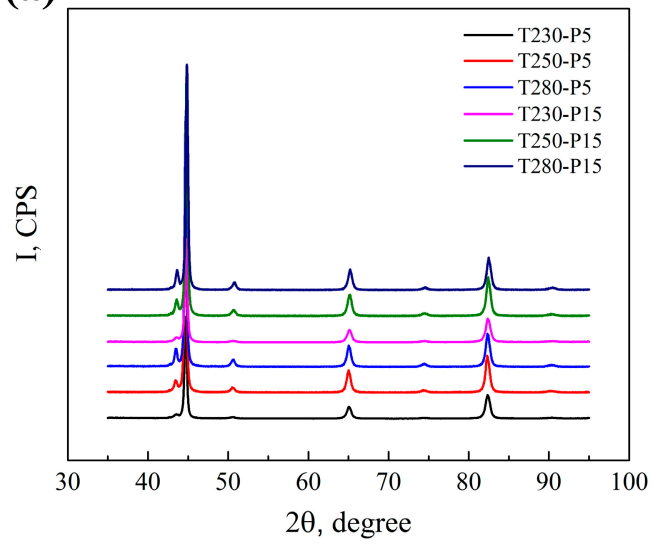

(b)

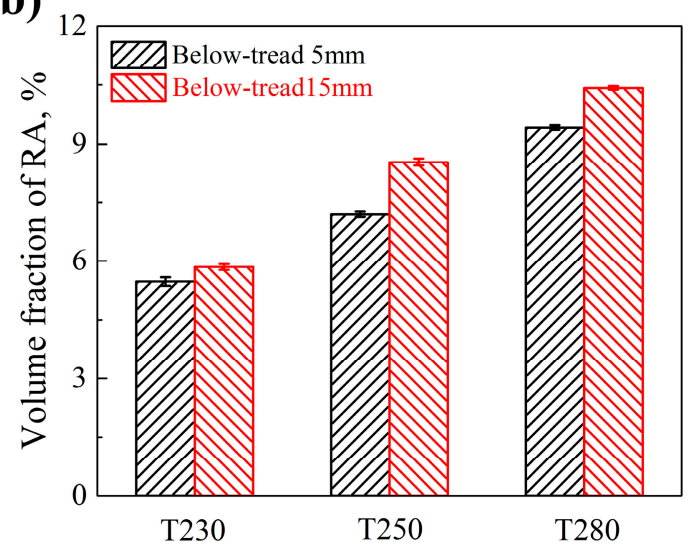

(c)

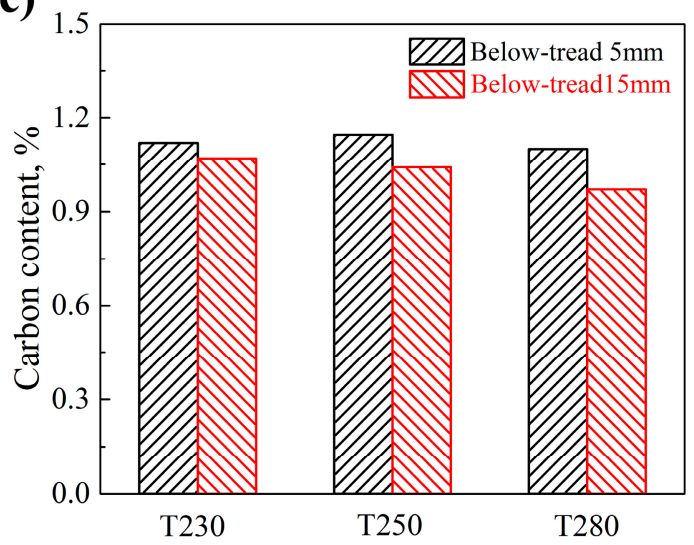

Figure 5. XRD analysis results: (a) XRD spectra; (b)Volume fraction of retained austenite; (c) Carbon content of retained austenite.

\subsection{Effect of the Microstructures on the Impact Toughness}

EBSD results are presented in 6,7 to discuss the effect of microstructures on the impact toughness. Figure 6 indicates the grain boundaries (red lines: $2-5^{\circ}$, green lines: $5-15^{\circ}$, blue lines: $>15^{\circ}$ ) of samples at the positions of $5 \mathrm{~mm}$ and $15 \mathrm{~mm}$ below rail tread treated by different controlled-cooling processes.

As shown in Figure 7, the samples of P5 have a higher proportion of high-angle grain boundaries (misorientation $>15^{\circ}$ ) than the samples of P15. The grain with high-angle grain boundaries (HAGBs) is described as effective grain, as they play an important role in blocking crack propagation [21]. In lath martensite, the prior austenite grain is divided into several martensite packets with the same habit plane, and each martensite packet is divided into several martensite blocks with close orientation. 
The boundaries of packet and block are both high-angle grain boundaries [25,26]. The smaller the size of packet and block per unit area, the higher the fraction of the high-angle grain boundaries. The effective grain size of the P5 samples is smaller than that of the P15 samples due to the faster cooling-rate, which may improve the fraction of HAGBs [27]. The further transformation of retained austenite after the spray controlled-cooling process makes some filmy RA transform into filmy M/A constituents with more HAGBs. High-angle grain boundaries have much more grain boundary energy than that of low-angle grain boundaries because a greater number of atoms deviate from its equilibrium position. The irregular arrangement of the atoms may cause the directions of crack propagation to change multiple times and much more crack propagation energy to be consumed [28]. Therefore, HAGBs can be more effective to force the crack to change the propagation directions, hinder the cracks propagation and improve impact toughness. As such, the impact toughness of the low-carbon B/M multiphase rail steel is greatly affected by the fraction of HAGBs.
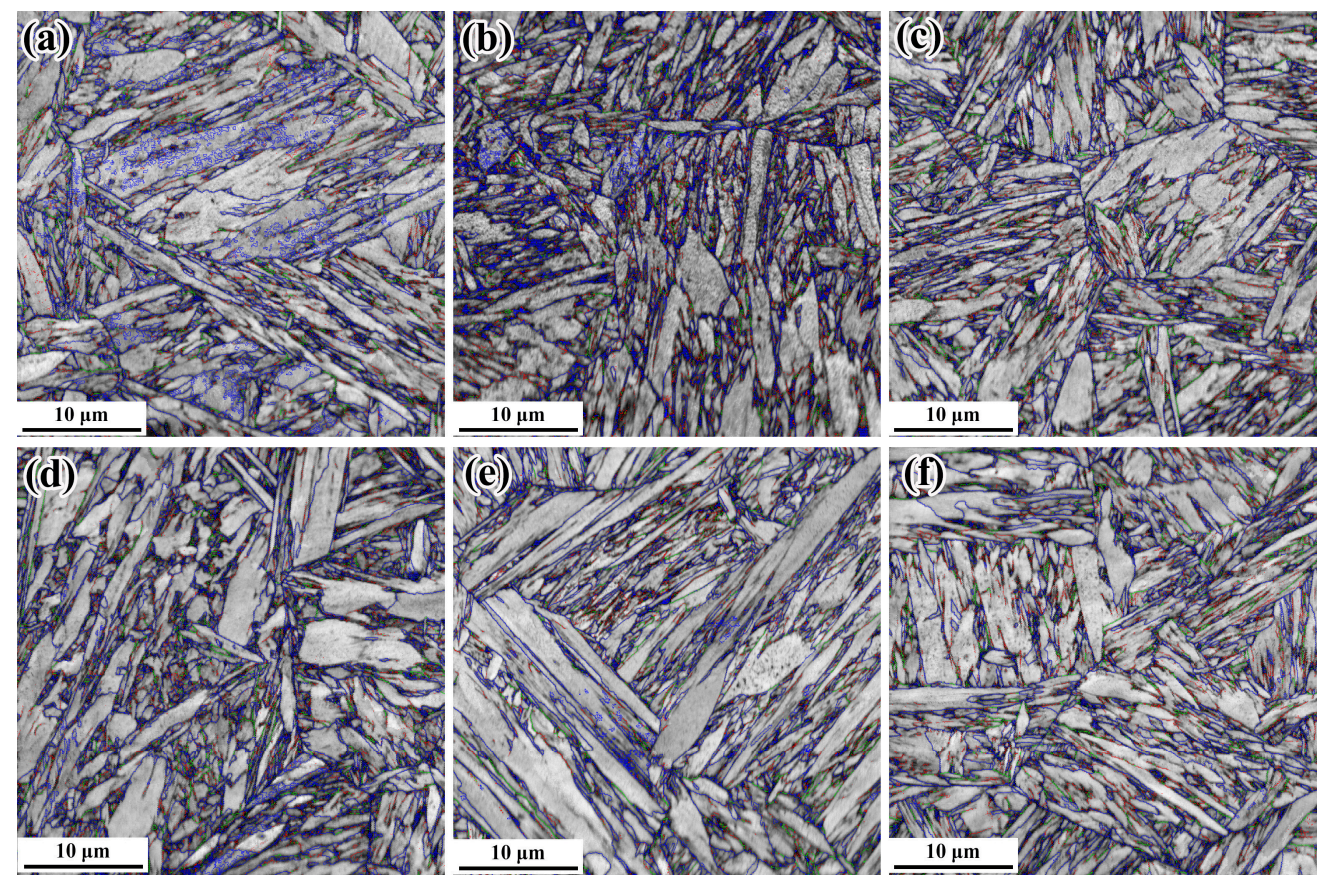

Figure 6. The grain boundaries of samples at the positions of $5 \mathrm{~mm}$ and $15 \mathrm{~mm}$ below rail tread treated by different process: (a) T230-P5; (b) T250-P5; (c) T280-P5; (d) T230-P15; (e) T250-P15; (f) T280-P15.

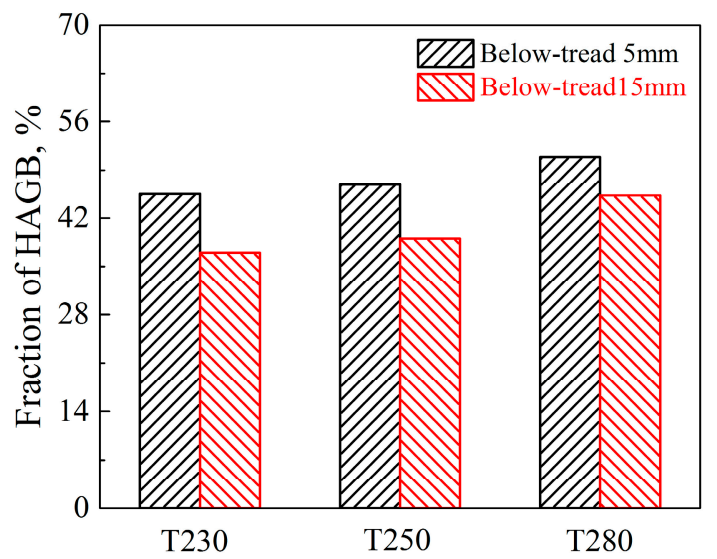

Figure 7. Fraction of high-angle $\left(>15^{\circ}\right)$ grain boundaries (HAGBs). 


\section{Conclusions}

In the present work, the relationship between the microstructures and mechanical properties of the $\mathrm{B} / \mathrm{M}$ multiphase rail treated by the controlled-cooling process has been investigated and analyzed. The controlled-cooling processes after rolling was simulated by finite element modeling. The main conclusions can be summarized as follows:

(1) The samples of P5 exhibit greater toughness than the samples of P15 due to the filmy retained austenite with higher carbon content and the smaller effective grain with high-angle boundary.

(2) The B/M multiphase rails treated by the controlled-cooling process with different finish-cooling temperatures exhibit a good combination of tensile strength (above $1320 \mathrm{MPa}$ ) and impact toughness (above $90 \mathrm{~J}$ ). This work provides scientific and systematic guidance for the development of high strength and toughness rail.

Author Contributions: Conceptualization, J.Q. and M.Z.; methodology, J.Q. and M.Z.; validation, J.Q.; investigation, J.Q.; resources, M.Z.; data curation, J.Q. and M.Z.; writing-original draft preparation, J.Q.; writing-review and editing, M.Z.; supervision, Z.T., G.G. and B.B.

Funding: The research was funded by the National Key Research and Development Program of China (2017YFB0304504), Fund of Key Laboratory of Advanced Materials of Ministry of Education (No. XJCL201908), and National Key Basic Research Program of China (2015CB654804).

Conflicts of Interest: The authors declare no conflict of interest.

\section{References}

1. Aglan, H.; Liu, Z.; Hassan, M.; Fateh, M. Mechanical and fracture behavior of bainitic rail steel. J. Mater. Process. Technol. 2004, 151, 268-274. [CrossRef]

2. Zhang, Y.; Xu, Z.; Zhao, X.; Gao, G.; Hui, W.; Weng, Y. Hydrogen embrittlement behavior of high strength bainitic rail steel: Effect of tempering treatment. Eng. Fail. Anal. 2018, 93, 100-110. [CrossRef]

3. Yu, Y.; Gu, J.; Xu, L.; Shou, F.; Bai, B.; Liu, Y.; Liu, Y. Very high cycle fatigue behaviors of Mn-Si-Cr series Bainite/Martensite dual phase steels. Mater. Des. 2010, 31, 3067-3072. [CrossRef]

4. Singh, U.; Roy, B.; Jha, S.; Bhattacharyya, S. Microstructure and mechanical properties of as rolled high strength bainitic rail steels. Mater. Sci. Technol. 2001, 17, 33-38. [CrossRef]

5. Zhang, F.; Zheng, C.; Lv, B.; Wang, T.; Li, M.; Zhang, M. Effects of hydrogen on the properties of bainitic steel crossing. Eng. Fail. Anal. 2009, 16, 1461-1467. [CrossRef]

6. Wu, D.; Li, Z.; Lü, H.-S. Effect of Controlled Cooling After Hot Rolling on Mechanical Properties of Hot Rolled TRIP Steel. J. Iron Steel Res. Int. 2008, 15, 65-70. [CrossRef]

7. Yu, X.G.; Hao, X.; Miao, R. Numerical Simulation Analysis of H-Beam Steel Controlled Cooling. Appl. Mech. Mater. 2013, 395, 1184-1189. [CrossRef]

8. Milenin, A.; Pernach, M.; Rauch, Ł.; Kuziak, R.; Zygmunt, T.; Pietrzyk, M. Modelling and optimization of the manufacturing chain for rails. Procedia Engergy 2017, 207, 2101-2106. [CrossRef]

9. Kang, H.; Wu, D.; Zhao, X.-M. Surface Temperature Change of U75V 60 kg/m Heavy Rail During Heat Treatment. J. Iron Steel Res. Int. 2013, 20, 33-37. [CrossRef]

10. Wang, K.; Tan, Z.; Gao, G.; Gui, X.; Misra, R.D.; Bai, B. Ultrahigh strength-toughness combination in Bainitic rail steel: The determining role of austenite stability during tempering. Mater. Sci. Eng. A 2016, 662, 162-168. [CrossRef]

11. Han, S.Y.; Shin, S.Y.; Lee, S.; Kim, N.J.; Bae, J.-H.; Kim, K. Effects of Cooling Conditions on Tensile and Charpy Impact Properties of API X80 Linepipe Steels. Met. Mater. Trans. A 2009, 41, 329-340. [CrossRef]

12. Qiao, Y. Modeling of resistance curve of high-angle grain boundary in Fe-3 wt.\% Si alloy. Mater. Sci. Eng. A 2003, 361, 350-357. [CrossRef]

13. Hwang, B.; Kim, Y.G.; Lee, S.; Kim, Y.M.; Kim, N.J.; Yoo, J.Y. Effective grain size and charpy impact properties of high-toughness X70 pipeline steels. Met. Mater. Trans. A 2005, 36, 2107-2114. [CrossRef]

14. Sugimoto, K.-I. Fracture strength and toughness of ultra high strength TRIP aided steels. Mater. Sci. Technol. 2009, 25, 1108-1117. [CrossRef] 
15. Gao, G.; Zhang, H.; Gui, X.; Luo, P.; Tan, Z.; Bai, B. Enhanced ductility and toughness in an ultrahigh-strength $\mathrm{Mn}-\mathrm{Si}-\mathrm{Cr}-\mathrm{C}$ steel: The great potential of ultrafine filmy retained austenite. Acta Mater. 2014, 76, 425-433. [CrossRef]

16. Zhao, P.; Zhang, B.; Cheng, C.; Misra, R.K.; Gao, G.; Bai, B.; Weng, Y. The significance of ultrafine film-like retained austenite in governing very high cycle fatigue behavior in an ultrahigh-strength $\mathrm{MN}-\mathrm{SI}-\mathrm{Cr}-\mathrm{C}$ steel. Mater. Sci. Eng. A 2015, 645, 116-121. [CrossRef]

17. Zhao, Y.; Tan, Y.; Ji, X.; Xiang, Z.; He, Y.; Xiang, S. In Situ Study of Cementite Deformation and Its Fracture Mechanism in Pearlitic Steels. Mater. Sci. Eng. A 2018, 731, 93-101. [CrossRef]

18. Chen, C.; Yen, H.-W.; Kao, F.; Li, W.; Huang, C.; Yang, J.; Wang, S. Precipitation hardening of high-strength low-alloy steels by nanometer-sized carbides. Mater. Sci. Eng. A 2009, 499, 162-166. [CrossRef]

19. Natori, M.; Tsuchiyama, T.; Takaki, S. Grain Boundary Bulging during Tempering in Lath-Martensitic Steel. Mater. Sci. Forum 2007, 558, 277-281. [CrossRef]

20. Li, Q.G.; Huang, X.F.; Huang, W.G. Microstructure and mechanical properties of a medium-carbon bainitic steel by a novel Quenching and Dynamic Partitioning (Q-DP) Process. Mater. Sci. Eng. A 2016, 662, 129-135. [CrossRef]

21. Wang, K.; Tan, Z.; Gao, G.; Gao, B.; Gui, X.; Misra, R.D.; Bai, B. Microstructure-property relationship in bainitic steel: The effect of austempering. Mater. Sci. Eng. A 2016, 675, 120-127. [CrossRef]

22. Yuan, L.; Ponge, D.; Wittig, J.; Choi, P.; Jiménez, J.A.; Raabe, D. Nanoscale austenite reversion through partitioning, segregation and kinetic freezing: Example of a ductile $2 \mathrm{GPa} \mathrm{Fe}-\mathrm{Cr}-\mathrm{C}$ steel. Acta Mater. 2012, 60, 2790-2804. [CrossRef]

23. Gao, G.; Zhang, H.; Gui, X.; Tan, Z.; Bai, B.; Weng, Y. Enhanced strain hardening capacity in a lean alloy steel treated by a "disturbed" bainitic austempering process. Acta Mater. 2015, 101, 31-39. [CrossRef]

24. Ohmori, Y.; Tamura, I. Epsilon carbide precipitation during tempering of plain carbon martensite. Met. Mater. Trans. A 1992, 23, 2737-2751. [CrossRef]

25. Morito, S.; Tanaka, H.; Konishi, R.; Furuhara, T.; Maki, T. The morphology and crystallography of lath martensite in Fe-C alloys. Acta Mater. 2003, 51, 1789-1799. [CrossRef]

26. Maki, T.; Tsuzaki, K.; Tamura, I. The morphology of microstructure composed of lath martensites in steels. Trans. ISIJ 1980, 20, 207-214.

27. Yang, Z.; Liu, Z.; He, X.; Qiao, S.; Xie, C. Effect of microstructure on the impact toughness and temper embrittlement of SA508Gr.4N steel for advanced pressure vessel materials. Sci. Rep. 2018, 8, 207. [CrossRef] [PubMed]

28. Wang, K.; Gu, K.; Miao, J.; Weng, Z.; Wang, J.; Tan, Z.; Bai, B. Toughening optimization on a low carbon steel by a novel Quenching-Partitioning-Cryogenic-Tempering treatment. Mater. Sci. Eng. A 2019, 743, 259-264. [CrossRef]

(C) 2019 by the authors. Licensee MDPI, Basel, Switzerland. This article is an open access article distributed under the terms and conditions of the Creative Commons Attribution (CC BY) license (http://creativecommons.org/licenses/by/4.0/). 